\title{
Invirtiendo la ruta: procesos de retorno de los ecuatorianos en España
}

\section{Reversing the path: the return process of ecuadorians in Spain}

\author{
Fina Antón Hurtado ${ }^{1}$
}

fmanton@um.es

Claudio Matarazzo ${ }^{2}$

claudio85matarazzo@gmail.com

\begin{abstract}
Resumen
Este trabajo es un análisis del cambio en los flujos migratorios Norte-Sur, concretamente las relaciones migratorias entre España y Ecuador, que han sido generadas por las dinámicas económicas producidas en el contexto global, el cual ha determinado la inversión de las corrientes migratorias. El texto permite viajar a través de la crisis Europea (y sus consecuencias) hasta analizar los cambios sociales y económicos que han transformado la República del Ecuador. La contraposición a los modelos de desarrollo neo-liberales y las políticas del Buen Vivir, han invertido el país de ser una nación de emigrantes a ser receptor de inmigrantes.

El tema es de máxima actualidad, por eso se necesita un aproximación antropológica que nos permita entender los cambios que están en la raíz de la transformación de los modelos de interacción económica y sociocultural.
\end{abstract}

\section{Palabras claves}

Antropología, migración, crisis, vivienda, desarrollo, buen vivir, cambio.

\begin{abstract}
This work is a representation of current changes between North-South migration flows. In particular analyzes migration relations between Spain and Ecuador, that have been generated by economic dynamics produced in the global context. The change in this context, has determined the reversal of migration flows. The text permit travel across the European crises (and its consequences) to analyze the social and economic changes that have transformed the Republic of Ecuador. The opposition to neo-liberal models of development and policies of Good Living, have invested the country to be a nation of emigrants to receiving immigrants.
\end{abstract}

The topic is of extremely current, therefore continuous analysis is needed to understand the changes that are at the root of the transformation of the models of economic and social interaction.

\section{Keywords}

Migration, crisis, housing, development, good living, exchange.

Forma sugerida de citar: Antón Hurtado, Fina, \& Matarazzo, Claudio (2015). Invirtiendo la ruta: procesos de retorno de los ecuatorianos en España. Universitas, XIII (23), pp. 35-64.

1 Profesora Titular de Antropología Social. Universidad de Murcia (España).

2 Doctorando de Antropología Social. Universidad de Murcia. 


\section{Introducción}

La especie humana fue nómada desde sus orígenes, y fue la agricultura la que propició la sedentarización porque facilitaba la continuidad en el sustento. Desde la Economía, como disciplina, se formularon una serie de teorías sobre la migración que olvidaban el origen nómada de nuestra especie, considerando que los seres humanos establecen una serie de vínculos con su comunidad y el entorno que no les inducen a migrar, por eso las teorías migratorias de los economistas definen la migración como una "patología social" (Sutcliffe, 1998). Nosotros entendemos que la curiosidad de los humanos y nuestro afán por ir hacia el horizonte han configurado a la movilidad como una constante en nuestra especie a lo largo del tiempo. La decisión de migrar supone la asunción de un alto riesgo y de un elevado coste tanto económico como personal, pero siguen siendo millones de personas en el mundo las que están dispuestas a asumirlo.

El fenómeno de la migración internacional no es nuevo, aunque su presencia en los medios de comunicación ha supuesto una amplificación del fenómeno. Si atendemos a los datos que nos facilita el Programa de Naciones Unidas para el Desarrollo (PNUD, 2009) la gran mayoría de los desplazamientos de personas que suponen un cambio en el lugar de residencia habitual, es intranacional. El PNUD calcula 740 millones de migrantes internacionales frente a los 200 millones internacionales, y de estos, sólo 70 millones de personas habrían emigrado de un país en vías de desarrollo a otro desarrollado. El informe de la PNUD también desmiente la percepción social que se tiene sobre el aumento de las migraciones internacionales en un contexto globalizado, porque según el informe, el porcentaje de migrantes internacionales se ha mantenido estable en un $3 \%$ en los últimos 50 años.

Este artículo analiza la inversión de ruta en el círculo migratorio "Sur-Norte-Sur", tomando como punto central de análisis el pueblo ecuatoriano, el cual ha estado viviendo en los últimos años (sobre todo desde 2006) un cambio estructural de su país. En consecuencia se han modificado los movimientos migratorios que se caracterizaron por una fuerte presencia de la comunidad ecuatoriana en Europa, la gran mayoría vinculada a España.

La migración internacional, como consideración general, es la consecuencia de una fuerte desigualdad entre el país de origen y el país de destino, el cual puede atraer a los inmigrantes por diferentes causas que influyen en la decisión de emigrar. Cuando esta diferencia se reduce o se transforma, el fenómeno migratorio también se modifica. El migrante busca la estabilidad y las oportunida- 
des para acceder a los recursos que deberían garantizarse universalmente. Estos cambios y la adaptación a ellos son fruto de la nueva economía de escala mundial que se ha desencadenado en las últimas décadas de desarrollo neoliberal. Castells la denomina "informacional y global".

Es informacional porque la productividad y competitividad de las unidades de esta economía (ya sean empresas, regiones naciones) depende fundamentalmente de su capacidad para generar, procesar y aplicar con eficacia la información basada en el conocimiento. Es global porque la producción, el consumo y la circulación, así como sus componentes (capital, mano de obra, materias primas, gestión, información, tecnología, mercados), están organizados a escala global... (Castells, 2005, p. 111).

Lógicamente el factor económico no es el único que influye en la decisión personal de querer emigrar a otro lugar, lo psicológico es determinante. El estudio de las estrategias migratorias contempla los vínculos de parentesco, las alianzas y las relaciones personales.

En relación al trabajo, como elemento de llamada a la inmigración, compartimos la idea de Manuel Castells, cuando dice que aunque la economía se haya globalizado y los distintos factores de producción se han internacionalizado generando redes de conocimiento e información, este proceso es más complicado para el trabajo no especializado. La mayoría de los inmigrantes no tienen especialización y el mercado de trabajo no cualificado está fuertemente limitado por las barreras nacionales y las fronteras. Con esto queremos destacar que aunque el capital es global la mayoría del trabajo es local, excepto en algunos sectores donde el nivel de explotación es muy alto como, en el caso de los inmigrantes ecuatorianos en España que trabajan en el sector doméstico, agrícola y de la construcción. "Solo una mano de obra especializada de elite, de gran importancia estratégica, está verdaderamente globalizada" (Castells, 2005, p. 168).

Acabamos de referirnos a la migración de los ecuatorianos en España, pero observamos un nuevo cambio que está afectando a la permanencia de este colectivo en el territorio español. Este cambio no refiere solo a los flujos migratorios, sino también a los modelos de desarrollo económico-social, concretamente al modelo del "Buen Vivir" que es un elemento característico del proceso de cambio de la República del Ecuador. Este modelo de desarrollo ha estado presente durante siglos en la cultura Kichwa y se le llamaba Sumak kawsay. Recientemente ha sido recuperado en la Constitución ecuatoriana del 2008 y en la boliviana de 2009. Este concepto, en contraposición al modelo neoliberal de 
desarrollo, es asumido por la Constitución del Ecuador y a través de los artículos 12 a 34 y del 275 a 278 (Constitución del Ecuador, 2008).

El presidente Rafael Correa ha retomado esta sabiduría popular de la cultura indígena para incorporarla a la Constitución y fomentar el diseño de planes de desarrollo llamados Planes Nacionales para el Buen Vivir (PNBV) 2009-13 y 2013-17. Es muy interesante observar las diferencias que existen en los modelos de desarrollo entre las dos regiones del mundo que estamos comparando y cómo estas diferencias repercuten en el fenómeno que queremos analizar: el cambio en los flujos migratorios relacionado con el acceso a la vivienda.

Nos referiremos al derecho al "hábitat y vivienda" como argumento central en el proceso de retorno. Será este proceso de cambio, el foco central de análisis de este artículo; es un cambio cultural propiciado por el cambio económico, que requiere capacidad de adaptación por parte de un colectivo que intenta adaptarse al entorno en el que vive. Al mismo tiempo es un cambio que se hizo posible, por las dinámicas de internacionalización del mercado y por las redes que estimulan y transfieren la información.

En este proceso de retorno de los ecuatorianos, la comunicación familiar y la trasformación del nivel informativo ha sido decisiva y podemos considerarla tan importante como el propio crecimiento económico de este país andino. Además este cambio ha sido propiciado por un aumento del desempleo en España. Las recetas neoliberales europeístas no han sido capaces de resolver el problema del paro. Como dice Ulrich Beck: "quien con la ayuda de la drástica medicina neoliberal pretende hacer disminuir el paro, crea (y agudiza) nuevos problemas...Han reducido el problema del paro a (y lo han cambiado por) una cuestión de bajos sueldos, baja productividad, un nivel bajo de cobertura, una desigualdad en los sueldos cada vez mayor y, sobre todo en EE.UU., de un índice de criminalidad en preocupante Aumento" (Beck, 2000, p. 53).

Analizando más en detalle lo que está pasando en España, los ciudadanos están atravesando desde 2007 una crisis económica que ha generado uno de los fenómenos más duros e incoherentes con la democracia: el problema de los desahucios, donde los ecuatorianos también han sufrido las consecuencias, teniendo que dejar su casa y quedando atrapados en una deuda que no permite salir de la condición de "esclavitud". Esto generó un conflicto internacional que obligó al actual presidente del Ecuador, Rafael Correa, a organizar un modelo de "salvaguarda" de los ecuatorianos en España, además de empezar un programa de retorno financiado por el mismo Gobierno. Como diría Ulrich Beck estos cambios derivan de la instauración de la lógica del "riesgo" como componente 
de desarrollo y crecimiento europeos, tanto de la sociedad como de la economía (nacional o global). Se da más importancia a políticas económica basada en el riesgo, como si se estuviera jugando un partido de póker, que a políticas que se dediquen a contrarrestar la desigualdad social y a fomentar el bienestar. Digamos que Ecuador tiene un menor "nivel de riesgo" en sus políticas, que son esenciales para la estabilidad humana. Por ejemplo en el sector agrícola, "la agricultura se convierte de este modo en el reino de los venenos que amenazan la vida de las plantas, los animales y los seres humanos" (Beck, 1998, p. 88).

Este artículo se estructura en base a tres entornos analíticos: la crisis de occidente como causa y principio del cambio, las modificaciones de los flujos migratorios Norte-Sur, y la vivienda como derecho indiscutible y fundamental. La perspectiva antropológica permitirá comprender mejor cómo numerosos colectivos de poblaciones distintas, que han tomado decisiones diferentes, sufren por los cambios impuestos por el modelo económico-cultural neoliberal considerado por occidente como el modelo de desarrollo único y global. A partir de la crisis este pensamiento único está empezando a resquebrajarse ante las alternativas y el crecimiento de los países "bolivarianos" que ponen en tela de juicio los principios neoliberales que tanto glorifican los mercados financieros de occidente.

\section{Desde el principio hasta el cambio: la salida y el retorno}

El desarrollo inicial de este fenómeno migratorio se manifiesta a finales de los noventa, cuando España estaba situada en un contexto socioeconómico de crecimiento en el que la mano de obra barata de inmigrantes no comunitarios fue uno de los motores de crecimiento del país. Paralelamente, a finales de los noventa, Ecuador sufre una de las crisis más graves de su historia que afecta al país, tanto desde el punto de vista sociopolítico, como del económico. En 1994 se reforma el sistema financiero de Ecuador provocando una liberalización financiera. La entrada de capitales brinda seguridad al desarrollo. Estos hechos generan un aumento acelerado de créditos (entorno a un $80 \%$ nominal) por parte de las empresas y entidades financieras. En 1998 se manifiestan gravemente los efectos acumulados de la situación económica del país y su alto endeudamiento. En 1999 y 2000 el sistema financiero nacional fue afectado por el cierre o transferencia al Estado de más de la mitad de los principales bancos del país. Ello se traduce en un nuevo movimiento migratorio internacional que alcanzaría una magnitud sin precedentes con un destino específico: el Estado español. 
"A principios de 1998 el número de migrantes ecuatorianos que residía en el Estado español no era significativo, mientras que en el 2001 llegan a ser más de 135000 personas" (Ministerio del Interior de España 2002). Cuando hablamos de "crecimiento español" nos referimos concretamente al sector de la construcción, el cual generó la burbuja inmobiliaria que estalla en 2007 desencadenando la crisis económica y financiera más grave del país.

Volviendo al principio, a finales de los años 90, España (aprovechando las relaciones de poder y las crisis socioeconómicas que generan una demanda de emigrantes en búsqueda de estabilidad económica), necesitaba mano de obra, especialmente para trabajar en el sector agrario. En este contexto se produce la llegada en 1998, de un contingente de ecuatorianos al mercado de trabajo agrícola en la provincia de Murcia (España); posteriormente se registra una llegada masiva y las trayectorias socio-espaciales también se destinan a las grandes ciudades como Madrid y Barcelona.

Conjuntamente al proceso de transmisión de la información se consolida la constitución de redes de parientes y vecinos que se convierten en fuente de información y seguridad para impulsar la migración. En este contexto cobra especial relevancia la figura del "chulquero (prestamista), eran gestores de pasaportes y permisos de migración y agencias de viaje que tramitan papeles, gestionan pasajes y "paquetes laborales", prometen traslados y contratos de trabajo a cambio de altos intereses; así entran en las cadenas familiares y dan forma a las primeras redes migratorias en los lugares de origen" (Pedone, 2002, p. 61).

Se entiende que, hasta el principio de la "crisis de occidente" los ecuatorianos se han inserido plenamente en la sociedad española y han ido atrayendo a más familiares, hasta que se generó la situación actual. En general:

Las migraciones internacionales han cobrado mayor fuerza en las últimas décadas a raíz de las diversas transformaciones suscitadas por los cambios económicos, tecnológicos y sociales que se generan como producto de la globalización. La globalización de la economía ha propiciado que la brecha de las desigualdades entre los países del centro y de la periferia se extienda sin control, conduciendo a la producción y la ubicación de la riqueza en pocos Estados y al deterioro de las condiciones de vida de la mayoría de la población mundial, sumado a una serie de problemas coyunturales por los que atraviesan los Estados pobres (Montero, 2006, p. 36).

Después de EE.UU. España fue el segundo país de destino preferido por los emigrantes ecuatorianos hasta el año 2008, mientras que ahora ha descendido 
al $4^{\text {a }}$ puesto. La presencia de la comunidad ecuatoriana ha permanecido al alza durante la época de crecimiento económico español, constituyéndose como uno de los grupos más influyentes en la población inmigrante. La Región de Murcia fue la que tuvo la mayor tasa relativa de inmigrantes ecuatorianos, en relación a la población autóctona. A partir de 2008 las llegadas de ecuatorianos a España han empezado a disminuir. Según los datos que nos han facilitado por el INEC (Instituto Nacional de Estadística y Censos del Ecuador), actualizados en 2013, se puede observar que ha habido un aumento en las entradas de ecuatorianos procedentes España después del 2008 (Tabla 1). Al mismo tiempo el número de ecuatorianos que salían de Ecuador para dirigirse a España se ha mantenido siempre inferior o los que regresaban. Podemos apreciar más el cambio que se ha producido en la temporada 2008 y 2013, con el gráfico 1, elaborado a partir de la Tabla 1 que representa la transformación que se está produciendo (Gráfico 1). Se puede observar cómo desde 2008, las salidas de ecuatorianos hacia España han ido disminuyendo, a excepción del repunte del 2011, pero que luego volverá a bajar en los años sucesivos. Podemos afirmar que esta tendencia descendente es la que predomina en la transformación de los movimientos migratorios entre estos dos países. Asimismo esta tendencia negativa ha sido acompañada por una tendencia positiva hacia el retorno (manteniéndose siempre superior a las llegadas a España durante el periodo analizado) con un pico máximo en el 2012. En la Tabla 2 están representados los datos relativos a la bajada del flujo de inmigración de ecuatorianos hacia España hasta el 2014. En el Gráfico 2 se aprecia cómo la tendencia negativa descrita anteriormente se hace constante también en el periodo 2008-2014.

La inversión de la ruta en los procesos migratorios Norte-Sur empieza a consolidarse y se hace realidad a través de estos fenómenos en los que están inmersos España y Ecuador. Esta tendencia inversa, está respaldada por una trasformación de España que pasa a ser un país de acogida a ser un país de emigración hacia la República del Ecuador. El "retorno" del colectivo ecuatoriano debe entenderse, no solo como fenómeno demográfico, sino como una reacción llena de significado simbólico que se manifiesta a través de las redes sociales transnacionales entretejidas por los migrantes durante todo el proceso migratorio. La red de vínculos familiares transnacionales es decisiva tanto para el proceso de salida como para la reintegración en el país de origen y los cambios experimentados en ambos lados (en el migrante y en los que no migraron) exigen una renegociación de los roles de género (Herrera, 2004). 
Podemos situar el proceso simbólico de retorno en tres escenarios diferentes: El primero refiere a que la convicción de retornar a Ecuador está presente desde el principio y permanece a lo largo de todo el proceso migratorio; el segundo es debido a las circunstancias económicas desfavorable y el tercero viene condicionado por la presencia de enfermedades o circunstancias familiares graves. A través del trabajo de campo, hemos podido registrar la importancia que el arraigo tiene en los movimientos migratorios. Son muchos los inmigrantes que inician este proceso con la convicción de volver a su país cuando consigan sanear su economía, pero existe un cambio de planteamiento cuando los hijos nacen en el país de acogida o se incorporan al sistema educativo del país. En estas circunstancias piensan que las posibilidades de promoción social son mayores en el país de acogida que en el de origen, pero en las circunstancias actuales de los países que nos ocupan, esta expectativa se dificulta en España y se favorece en Ecuador.

Los seres humanos, desde los orígenes de nuestra especie, hemos ido superando diferentes crisis, la novedad de la actual es que es polifacética y está sincronizada. La crisis se inició con la ruptura de la burbuja inmobiliaria, generando una crisis financiera que se convierte en económica afectando a los entornos productivos y llegando a los entornos sociales, en los que se ven afectadas las relaciones humanas, e incluso la concepción de nosotros mismos, generando una crisis institucional, de identidad y de valores. Paralelamente a estas crisis afrontamos a nivel global los retos alimentarios, demográficos, energéticos y medioambientales que obligan a un replanteamiento del concepto de "progreso", porque mal entendido, puede llevar al planeta al colapso ecológico. Un elemento que caracteriza a Ecuador y lo contrapone a España es la importancia que se confiere a la naturaleza como "realidad" indispensable en el proceso de vida. Hoy en día hay que tener en cuenta el desarrollo ecológico de un país y relacionarlo con el contexto internacional. Para entender mejor este concepto pongamos el ejemplo de la catástrofe nuclear de Chernóbil en el año 1986 que puso en riesgo a toda Europa con una nube toxica. Estos desastres ecológicos traspasan fronteras y afectan la vida diaria de las personas, tanto en sus comportamientos, como en sus conocimientos y percepciones del mundo. Estos son conceptos tan importantes que "la naturaleza y destrucción de la naturaleza, son producidas institucionalmente y definidas (en los "conflictos entre profanos y expertos") dentro de la naturaleza interiorizada industrialmente" (Beck, 2002, p. 48). También el concepto de "hábitat" utilizado junto con el de vivienda en la Constitución ecuatoriana del 2008, se refiere a algo muy distinto del solo concepto de "vivienda" que se utiliza en la Constitución española del 1978. El "há- 
bitat" ecuatoriano refiere a un espacio habitable tanto dentro como fuera de la vivienda que debe satisfacer las necesidades de las personas en su convivencia y en su integración en el entorno ecológico.

A continuación, analizaremos el derecho a la vivienda y el fenómeno de los desahucios en España, para poder vincular las crisis referidas más arriba con la transformación en los cambios migratorios y aportar criterios para comprender los acontecimientos que están motivando la "Inversión de ruta".

\section{Dos realidades: Crisis de la vivienda española y cambios en Ecuador}

Cuando hablamos de dos realidades diferentes nos referimos al contexto histórico del cual proviene la situación actual. Es bien sabido que ninguna actividad humana, y en general de la vida, surge por generación espontánea, todo tiene un proceso de gestación, que en Antropología se estudia asumiendo la perspectiva diacrónica. En el caso español nos encontramos con un sistema institucional que se remonta al siglo XV con las conquistas de nuevos territorios y el fortalecimiento del Estado-Nación. El encuentro entre dos mundos tan diferentes en su forma de entender la vida, hace que España, y en general, occidente, se sitúe en una posición predominante, determinando el desarrollo de intercambios económicos y culturales basados en la dominación del "otro". Estas dinámicas, mantenidas durante siglos, han determinado la constitución del sistema neoliberal actual, el cual persigue a nivel global la privatización y el uso de recursos sin límites en un mundo limitado y finito.

Actualmente en Europa, la crisis del estado del bienestar afecta tanto a autóctonos como a inmigrantes. La crisis hipotecaria ha afectado tanto a familias españolas como ecuatorianas y la población en general, al margen de su procedencia, está sufriendo las consecuencias de una legislación hipotecaria claramente injusta como denuncia el Tribunal de Luxemburgo, que considera que la ley deja en inferioridad de condiciones a los usuarios frente a los bancos. La población afectada por esta normativa en España ha sufrido uno de los dramas sociales más duros desde el inicio de la crisis, siendo muchísimas familias y personas obligadas a abandonar su vivienda por no poder cumplir con el pago de las cuotas mensuales de la hipoteca. En este sentido se ha generado un sentimiento de inseguridad dentro de la población en general ante la incapacidad de los gobernantes para garantizar el acceso a la vivienda. 
Al referirnos al sentimiento de seguridad relacionado con el hábitat apelamos a la sensación de que "Vivir en un entorno en el que las personas puedan sentirse seguras es la máxima garantía que podemos tener para llevar a cabo un proyecto de vida satisfactorio" (Antón Hurtado, 2013, p. 75). Este concepto de seguridad relacionado con un estado emocional es importante a la hora de analizar la constitución de grupos de ciudadanos afectados por la hipoteca, movilizados primero por sus sentimientos y luego por la formación racional de grupos de acción y participación democrática directa. Emoción, razón y conciencia van entrelazadas y son indispensable cada una para el desarrollo de las otras. El análisis antropológico nos permite comprender cómo el pensamiento racionalista ha permitido la promulgación de políticas económicas que no tienen en cuenta el estado emocional y los sentimientos de las personas. Así entendemos cómo ha sido posible que la legislación española obligue a los ciudadanos que han perdido su vivienda, a seguir pagando por ella, sin poder disfrutarla y siendo desahuciados.

Para situarnos contextualmente, resumiremos brevemente cómo ha sido posible que se haya generado esta falta de respeto a uno de los derechos fundamentales, recogidos en la Constitución española como es "el derecho a una vivienda digna". Empezamos aclarando que "poseer" algo es intrínseco a la cultura europea y norteamericana. Este proceso es típico de las sociedades occidentales especialmente de aquellas que privilegian el libre mercado, desde el cual se han instituido valores diferentes a los del pasado, como por ejemplo "ser lo que se posee". Entonces para ser hay que poseer y para poseer hay que consumir y para consumir hay que endeudarse. Los grupos bancarios españoles, hasta la explosión de la burbuja inmobiliaria, gozaban de mucha liquidez y empezaron a conceder préstamos aunque se tuvieran pocas garantías de recuperación de lo prestado. Por otro lado, muchas personas, que habían disfrutado de elevados salarios sobre todo en al sector de la construcción, creían que estos ingresos serían permanentes. También esta idea fue transmitida por el gobierno y los propios bancos, los cuales incentivaban con "préstamos fáciles" y transmitían la sensación de que pedir una hipoteca era algo sin consecuencias y que los clientes debían que confiar en ellos. En la mentalidad tradicional española los profesionales de la banca eran los que sabían qué cantidad de dinero podían prestar. Lo habitual en las décadas previas a la burbuja inmobiliaria, era que los clientes pidieran unas cantidades que los bancos siempre rebajaban. La anomalía surge cuando los usuarios solicitan unos préstamos cuyas cuantías son ampliadas por el banco. 
Los usuarios españoles de los préstamos bancarios partían de la base de que si los bancos, que son los que tienen el dinero, esto es, que son los que saben, les ofrecen una cantidad mayor, será porque están seguros de que la economía irá bien y los clientes podrán pagarlos. La manipulación del lenguaje hasta hacerlo ininteligible y el conocimiento por parte de las élites de poder, de la importancia que éste tiene en la gestión emocional de la toma de decisiones, tiene como consecuencia "la reticencia de los políticos y demás representantes de los poderes fácticos a usar determinadas palabras que refieren a una realidad que quieren ocultar, y la adopción de otras que enmascaran esa realidad, pero que se identifican como sinónimas con el objetivo de reducir la carga emocional que la población habría atribuido a lo largo de su proceso de enculturación" (Antón Hurtado, 2013, p. 80).

Las personas aceptan la hipoteca porque confían en los conocimientos y la profesionalidad de los bancos, pero cuando aparece la crisis inmobiliaria se enfrentan a la asunción exclusiva de las responsabilidades del pago de la hipoteca, sin que el banco se responsabilice de nada y con una legislación hipotecaria claramente injusta y anacrónica. Los bancos que conceden hipotecas son esencialmente especuladores financieros, financiando préstamos con el objetivo de ganar dinero a través de los intereses que genera la hipoteca. Así las entidades bancarias persiguen la deuda del hipotecado que ha perdido su vivienda, sin tener en cuenta, que el valor actual del inmueble ha bajado.

Respecto a la vivienda, consideramos pertinente la propuesta de Bourdieu acerca de cómo evolucionó, a partir de la segunda mitad del siglo XX, el sector de la vivienda y el modo en el cual se ha organizado un mercado de la vivienda relacionado con el proceso político de buscar proveer de techo a las familias. Bourdieu explica que el mercado de la vivienda se conforma a partir de políticas públicas que se desvinculan del proceso democrático para depender de los intereses de constructoras y de bancos (Bourdieu, 2003). En este proceso, el mercado de viviendas se incorpora a los programas políticos a partir de los planes de urbanismo que hacen suyas las condiciones de los promotores inmobiliarios y los bancos. Así se infunde en los compradores como proyecto de vida la compra de la vivienda con préstamo a largo plazo, lo que condiciona el futuro de las personas. Es como si existiera una predeterminación por parte de las entidades bancarias en definir o establecer los futuros comportamientos económicos de la población, para ajustarlos a sus intereses particulares. Unido a esto, observamos una dejación de la defensa de los derechos de los ciudadanos por 
parte de las instituciones políticas y se ha utilizado la crisis para aplicar las directrices de la "Troika europea" en detrimento de la soberanía popular.

Desde el 2007 hasta hoy el número de hipotecas concedidas en España ha bajado drásticamente y ha aumentado la cantidad de desahucios: por un lado se ha perdido confianza en el sistema de préstamo hipotecario y por otro lado ya no es tan fácil acceder a un crédito sin tener la garantía de que será devuelto. Sin perdernos en grandes cifras, destacamos que los datos de las hipotecas totales concedidas desde 2007 hasta 2014 (Tabla 3) en España reflejan una drástica bajada de los mismos. Esta tendencia negativa la representamos en el Gráfico 3, donde se evidencia el pico más alto de concesiones hipotecarias durante este periodo, en el año 2007, con 431043 hipotecas, que se reducen en el 2014 a 73044 hipotecas concedidas. El colectivo ecuatoriano se encuentra entre los afectados por la hipoteca y como respuesta el Gobierno del Ecuador promulgó el Programa de Retorno, facilitando a los compatriotas que así lo desearan, la vuelta a su país natal. Uno de los efectos de estas decisiones políticas del Gobierno ecuatoriano contra la persecución hipotecaria fue "que el Banco Pichincha España compró a Bankia 572 créditos al consumo por valor de 5,5 millones de euros. Unos préstamos de los que el 14\% de los titulares eran ecuatorianos. La operación se efectuó sin previo aviso y los clientes se enteraron por carta de que a partir de ese momento deberían "cumplir con sus obligaciones de pago" con una nueva entidad.

Yo no autoricé la cesión de mis datos, denuncia Aida. Los abogados de la Asociación intentan tranquilizar a los afectados. La transacción entre ambas entidades se produjo de la siguiente forma: Bankia identificó el riesgo impago de esas hipotecas y las vendió a Pichincha cuando los clientes todavía eran pagadores, asumiendo pérdidas pero ganando liquidez. Por su parte, a Pichincha le sirvió para introducirse en el mercado español. La operación fue benefíciosa para los bancos, pero no tiene por qué ser perjudicial para los clientes (Benito, 2012; www.elconfidencial.com).

Pero el nuevo banco que ha comprado las hipotecas por un precio del $10 \mathrm{o}$ del 15\% del valor real que están pagando los clientes, les pondrá unas condiciones duras para recuperar el préstamo. Los hipotecados tienen el derecho de "retracto", pero muchos lo desconocen y además hay un plazo muy breve tras la comunicación de la compra de la deuda por parte de la nueva entidad bancaria para poderlo ejercer. Este plazo es de 9 días desde la comunicación del cambio de titularidad del préstamo. Este derecho está declarado en el artículo 
1535 del Código Civil español. El uso que estas entidades hacen del tiempo entra en la lógica de la constitución de un sistema vital, en el cual la velocidad de acción asume un rol fundamental también a la hora de defender nuestros derechos. Esta aceleración del tiempo social e individual ha causado la pérdida de sentido en nuestra vida. Ya no hay tiempo para la reflexión y la plena interiorización del conocimiento, sino para el acato. Esta pérdida de sentido nos aboca a situaciones, muchas veces relevantes para nuestra vida, sin haber tomado una decisión personal, sino llevados por el vértigo de la velocidad y las circunstancias en las que estamos inmersos (Antón Hurtado, 2012). El Banco Pichincha "utilizó" esta falta de conocimiento y la imposición de los plazos de reacción, teniendo muy claro que sin estos elementos los ciudadanos tendrían muchas dificultades a la hora de tomar una decisión para la salvaguarda de sus intereses.

Toda esta situación en el mercado bancario se produce con una normativa sobe el derecho a una vivienda digna que se reconoce en el artículo 47 de la Constitución Española del 1978 (que se quiere modificar) y en el artículo 30 de la Constitución del Ecuador del 2008. Estos son artículos que se refieren al derecho a disfrutar de una vivienda digna, pero antes de analizarlos, es conveniente contextualizar la época histórica en la cual se escribieron. Estas dos constituciones llegan de dos entornos culturales muy diferentes: por un lado la Constitución española de 1978, proviene de un contexto histórico-político donde la reciente muerte del dictador Francisco Franco sitúa España en un contexto en el cual el término de frontera y territorio se articulan dentro de la estructura del Estado Nación que en la actualidad se está desvaneciendo dentro de un mundo globalizado. Como dice Ulrich Beck en la sociedad global actual las funciones de los Estados Nacionales ya se quedan atrás respecto a los problemas siempre más globalizados, dejando espacio a fuerzas supranacionales características de las sociedad del riesgo: "los riesgos producen nuevas desigualdades internacionales, por una parte entre el Tercer Mundo y los Estados industrializados, por otra parte entre los mismos Estados industrializados. Esas desigualdades no respetan el tejido de competencias del Estado nacional" (Beck, 1998, p. 29).

Veamos en el detalle estos dos artículos:

En el Artículo 47 de la Constitución Española de 1978 se dice:

Todos los españoles tienen derecho a disfrutar de una vivienda digna y adecuada. Los poderes públicos promoverán las condiciones necesarias y establecerán las normas pertinentes para hacer efectivo este derecho, regulando la utilización 
del suelo de acuerdo con el interés general para impedir la especulación. La comunidad participará en las plusvalías que genere la acción urbanística de los entes públicos.

En el Artículo 30 de la Constitución del Ecuador de 2008, se dice: "Las personas tienen derecho a un hábitat seguro y saludable, y a una vivienda adecuada y digna, con independencia de su situación social y económica”.

El artículo 47 de la Constitución Española restringe el derecho a la vivienda a "todos los españoles" lo que debe interpretarse teniendo en cuenta la importancia que la institución del Estado-Nación tiene en occidente que se reflejaba en un claro cierre de las fronteras dentro de un mundo donde el mercado global no tenía nada a que ver con el actual. El concepto de frontera además de conflictivo se hace vago y al mismo tiempo de difícil gestión ya que no se respetan los derechos humanos y se intenta rechazar el fenómeno de la inmigración, sobretodo norteafricana: como por ejemplo en las fronteras situadas en Ceuta y Melilla. Esta situación propicia la aparición de un mercado negro que controla en acceso a Europa, y fomenta la formación de mafias que controlan las rutas migratorias, muchas veces, a costa de la vida de miles de migrantes en el mar Mediterráneo.

Por otro lado y como hemos visto anteriormente, la influencia que los promotores inmobiliarios y los bancos tienen en la ejecución de las planes de vivienda dificulta, sino impide, que los gobiernos españoles puedan garantizar el cumplimiento de este artículo, porque la especulación urbanística es innegable en España y la participación de la población en las plusvalías generadas por los desarrollos urbanísticos es escasa, siendo los grandes beneficiados de esas plusvalías los promotores inmobiliarios, los banqueros y los políticos corruptos. Es muy relevante comprobar como el actual gobierno conservador en España protege los intereses privados de los bancos y las grandes corporaciones en detrimento de los intereses legítimos de la mayoría de la población. En España la persona que no pueda pagar su hipoteca, no solo pierde su casa, sino que está obligado a seguir pagándole al banco la deuda contraída aunque ya no viva en la vivienda, mientras que los agujeros financieros de los bancos los asume la población a través del rescate bancario, el "banco malo", los recortes asistenciales y educativos y la subida de impuestos.

Respecto al artículo 30 de la Constitución del Ecuador, lo primero que destaca es la humanidad, al atribuir el derecho a la vivienda a todas las "personas" sin distinción de nacionalidad ni de posición económico-social. La referencia al término "hábitat" supone incorporar una visión ecológica dentro de una legisla- 
ción basada en el respeto al territorio relacionado con la identidad de un pueblo. Próximo a este término podemos situar la categoría de "paisaje cultural" formulado por Álvarez Munárriz el cual afirma que:

Territorio y paisaje han devenido conceptos correlativos y la cultura territorial de una población se mide por la valoración que hace de sus paisajes. Implica un modelo de interpretación del territorio que incita a la protección y gestión sostenible de los espacios valiosos, indica la necesidad de un cambio de rumbo en nuestro estilo de vida, e invita a actuar sobre el medio ambiente con medidas prudentes e imaginativas (Álvarez Munárriz, 2011).

La incorporación de la seguridad como emoción propiciada por el acceso a una vivienda, que se transmite y refuerza a partir de la cohesión social que genera en la ciudadanía es una gran conquista especialmente en las sociedades inestables y del riesgo en la que vivimos. La seguridad que cohesiona al grupo "se sustenta en la comprensión y la confianza" (Antón Hurtado, 2013). Otro concepto clave de este artículo es el de "saludable" que aglutina una visión integral de la persona incorporando a la salud física, la salud mental. Recientes estudios de las ciencias del comportamiento han demostrado la repercusión que tienen en la percepción de la salud, el desarrollo de los seres humanos en espacios vitales adecuados y seguros. En contextos sometidos al cambio, tener un entorno cómodo y seguro es garantía de salud tanto física como mental.

Cuando ponemos en relación la realidad devastadora generada por la burbuja inmobiliaria, con el artículo 47 de la Constitución Española, es fácil evidenciar cómo el poder de las instituciones que nos gobiernan no ha sido capaz de impedir la especulación financiera en el sector de la construcción, permitiendo la difuminación del derecho fundamental a disfrutar de una vivienda digna y consecuentemente la pérdida de una serie de equilibrios sociales, comunitarios y personales esenciales para un sano desarrollo de los individuos. Como reacción a esta situación se constatan acciones ciudadanas que apoyan el restablecimiento de una justicia social hacia el respeto del artículo citado y de todos los derechos humanos fundamentales que se concreta en cambios estructurales en la construcción social y en la formación organizativa de los movimientos españoles que luchan para restablecer el respeto de los valores democráticos que tendrían que predominar por encima del poder económico, que ha abandonado la función instrumental de generador de bienestar. La comunidad ecuatoriana ha participado en la creación de tales movimientos en España, por ejemplo la 
PAH, Plataforma de Afectados para la Hipoteca, ya que han sido uno de los colectivos de inmigrantes más afectados por este fenómeno.

El Servicio de Asesoría Hipotecaria del Consulado Ecuatoriano de Murcia ha sido la tercera delegación del Gobierno ecuatoriano en España, que más ha trabajado para contrarrestar este fenómeno y ha atendido, en dos años, desde 2012 hasta finales de 2014, a 4573 afectados ecuatorianos residentes en la Región de Murcia. En total en el territorio español los consulados ecuatorianos han atendido hasta finales de 2014 a 19637 personas. Estas personas reciben asesoría jurídica gratuita que les permite renegociar con los bancos los tiempos del pago de la deuda o la dación en pago. Estos son datos muy relevantes para poder entender el nivel de involucración de los ecuatorianos en esta crisis española y la razón por la que muchos migrantes están regresando a su país.

La Ley Orgánica 732 del 2012 para la regulación de los Créditos para Vivienda y Vehículos, aprobada por Rafael Correa y su Gobierno, impide que los bancos españoles puedan perseguir a los ecuatorianos que han vuelto a Ecuador. Según el Ministro de Relaciones Exteriores y Movilidad Humana de Ecuador, Ricardo Patiño, se estima que las familias ecuatorianas afectadas durante la crisis económica en España fueron más de 10 000. Esto ha generado la reacción y la intervención del Gobierno de Rafael Correa en defensa de sus compatriotas emigrados. Una de estas reacciones ha sido el Programa de retorno que analizaremos más adelante. "Durante el primer semestre de 2014, los mayores descensos se dieron entre los peruanos (-14,8\%), los bolivianos (-14\%) y los ecuatorianos $(-12,6 \%)$, una tendencia que no ha cambiado desde el 2012..." (Betim, 2014). Según el INE (Instituto Nacional de Estadística de España) la población de ecuatorianos en España ha disminuido en 27014 personas en el primer semestre del 2014 y actualmente es de 187 025. ¿Cómo ha sido posible promover y apoyar un programa de ayuda tan ambicioso?

El avance en el desarrollo del Ecuador no ha sido solo económico, sino ideológico y social. Esto ha sido posible a través de una fuerte financiación en varios sectores públicos, como la sanidad, la educación y el respeto al medioambiente. El movimiento social que ha impulsado esta situación en los últimos diez años y bajo la presidencia de Rafael Correa, junto con el Movimiento Alianza PAIS, es "Revolución Ciudadana" que tiene sus bases ideológicas en el Socialismo del siglo XXI. El simbolismo de esta expresión es predominante en la nueva cultura ecuatoriana. No hay carretera donde no existan carteles que recuerdan que los logros que están ayudando al crecimiento del país han sido posibles solo gracias a esta "revolución ciudadana". Con esto se intenta generar 
un sentimiento de pertenencia y solidaridad, donde cada ciudadano es partícipe y activo en el cambio, promocionando la democracia directa y participativa. La realidad está un poco lejos del simbolismo, pero hay que admitir que el cambio que se ha generado en Ecuador en los últimos diez años ha sido el más potente de todos los países latinos donde se persigue el "sueño bolivariano" (Bolivia, Colombia, Ecuador, Panamá, Perú y Venezuela).

A nivel antropológico la creación de un mito referencial como fundador del sentimiento de seguridad es primordial para la creación de una identidad sólida y estable. Bien, lo que llamamos mitos se desarrollan para crear y mantener la solidaridad social, la cohesión del grupo, legitimar las instituciones y las prácticas sociales. Esto ha sido posible también gracias a la inversión que la República Ecuatoriana ha hecho en la calidad y mejora de la formación y todo lo relacionado con ella: infraestructuras, inversión en formación, tecnología, accesibilidad y también el conocimiento retornado desde otros países. El diferencial básico de una sociedad desarrollada reside en el conocimiento y en el grado de formación de sus trabajadores. Esta situación ha involucionado, especialmente en España, con una clara fuga de cerebros, especialmente intensa a partir del 2012, tras el ascenso del Partido Popular al gobierno de España y la aplicación de su política de recortes.

\section{Migración actual y transformación}

Para aclarar mejor los cambios que se están produciendo en la relación global entre norte y sur y concretamente, entre España y Ecuador, analizaremos los datos que nos han sido facilitados directamente por el INEC (Instituto Nacional de Estadística y Censo del Ecuador) -Tabla 4. Las entradas de ecuatorianos en país ascendieron en 2013 a 1143116 personas. En general, el Ministerio del Interior ecuatoriano desde el 2010 hasta mayo de 2014 registra un total de 4568145 salidas de ecuatorianos y 4554724 ingresos al país. Estos y otros datos estadísticos se revelaron en el taller, "Estadísticas de Migración en Ecuador - Realidad, Potencialidad y Perspectivas", que se desarrolló en Quito.

Las medidas tomadas por el Gobierno ecuatoriano resultan atractivas, no sólo para los propios ecuatorianos, sino también para los españoles, por eso se considera que las consecuencias son bidireccionales. España ya no es una nación preferida por los inmigrantes ecuatorianos y eso tiene consecuencias en los españoles. Como ejemplo de esta situación podemos referirnos a numerosas familias 
españolas que contrataron a mujeres ecuatorianas como trabajadoras domésticas, especialmente para el cuidado de a personas dependientes y niños. Por esta razón la crisis y el "cierre del giro migratorio", ha supuesto una pérdida de servicios en el nivel institucional micro (la familia) dentro de la sociedad española. Este apoyo era fundamental ya que los cambios impuestos por el neoliberalismo causaron una transformación de las estructuras familiares, generando la simplificación de las mismas y una modificación en las relaciones intrafamiliares.

Las estadísticas del Ministerio de Empleo español siguen mostrando el predominio de las mujeres ecuatorianas en las labores domésticas frente a los despidos masivos de los hombres ecuatorianos que trabajaban en el sector de la construcción, debido al pinchazo de la burbuja inmobiliaria. La inversión del flujo migratorio también afecta a los propios españoles que empiezan a salir del país para buscar unas condiciones de vida dignas.

El embajador de Ecuador en España, Miguel Calahorrano, cifra en al menos 50000 los retornados (hay en total 56466 ecuatorianos menos en España según el INE, pero también habla de miles con doble nacionalidad ecuatorianaespañola emigrados a Europa y que no cuentan en España como extranjeros. Dos universidades españolas están estudiando ahora por encargo de la embajada la salida de ecuatorianos de España. "Es para intentar saber qué está pasando con nuestra gente", señala el embajador (Carbajosa, 2014).

Resumiendo, entre las causas que han inducido a los ecuatorianos a volver a su país estaría la situación de crisis generalizada analizada anteriormente, la mejora de las condiciones económicas y sociales de Ecuador promovida por el presidente Correa, y la aprobación de un Plan de Retorno para poder regresar Ecuador, que consiste en garantizar a las personas que quieren regresar, ayudas económicas para el viaje de regreso y el traslado de los bienes acumulados durante la estancia en el extranjero. Según el Plan, los emigrantes que deseen regresar a su país también podrán beneficiarse del acceso a créditos para poder desarrollar empresas en Ecuador, y de facilidades para vivienda, educación y salud. Este Plan ha sido promulgado también para proteger los ciudadanos ecuatorianos de la normativa hipotecaria española y de la falta de recursos que esta misma generaba, quitando la posibilidad de seguir con un proyecto de vida dentro de España.

En el 2014, más de cien ecuatorianos se beneficiaron de las ayudas de retorno asistido del Vice Ministerio de Movilidad Humana, a través del Consulado General del Ecuador en Madrid. 
El Consulado General del Ecuador en Madrid dando cumplimiento a la garantía de los derechos fundamentales y el Buen Vivir de los ecuatorianos en el exterior, gestiona ayudas económicas para retornar a Ecuador. Los ciudadanos ecuatorianos que se encuentran en situación de vulnerabilidad, sin recursos económicos y que hayan decidido regresar al país pueden solicitar dichas ayudas. La concesión de las ayudas de retorno se realiza previo estudio socio-económico de la familia en España y en Ecuador. El Área de Vulnerabilidad de nuestra Misión Consular se encarga de realizar la valoración socio-económica en España, mediante una entrevista personal con el ciudadano interesado. Los compatriotas que solicitan las ayudas de retorno deben presentar la siguiente documentación:

-Formato "Solicitud de Pasajes" relleno (Descarga)

-Pasaportes ecuatorianos/ inscripción de nacimiento

-NIE o DNI. Original y fotocopia (en un solo folio copia de la documentación de todos los miembros de familia)

-Empadronamiento actualizado familiar/ colectivo

-Vida laboral actualizada

-Justificantes de ingresos: nóminas, pensiones, préstamos, certificados del INEM, ayudas, etc.

-Justificantes de egresos: contrato de alquiler, recibos de gastos básicos, deudas, renta, etc.

-Informes médicos, de discapacidad y/o psicológicos, si es el caso.

-Denuncias: si es víctima de violencia de género, desahucios de vivienda, embargos, etc.

-Documentos de otras ayudas recibidas: Caritas, Cruz Roja, etc.

-Movimiento bancario

-Informe socio-económico de los servicios sociales, si acude a los mismos”.

(Consulado General del Ecuador en Madrid; http://madrid.consulado.gob.ec/ apoyo-en-casos-de-vulnerabilidad/] 
En general América del Sur está "revolucionando" los fenómenos migratorios: se observa que en España las poblaciones con mayor descenso son las latinas provenientes de países andinos, Ecuador, Colombia, Perú y Argentina. "Aunque todas las nacionalidades registraron saldos migratorios negativos, las mayores reducciones en términos relativos se produjeron en la comunidad peruana (perdieron al 23,76\% de sus habitantes), colombiana (un 22,75\%), boliviana (un 22,22\%), ecuatoriana (20,96\%) y argentina (15,20\%)." (Agencia El País, 2014). Probablemente esto es un síntoma del cambio en las relaciones económicas supranacionales generado en parte por el descenso de las rentas en las clases bajas y medias y el aumento y la concentración de la riqueza en las clases más favorecidas, ampliando así las diferencias entre ricos y pobres en los países occidentales. También han influido los mensajes de los poderes públicos españoles para poner en práctica y facilitar el retorno de los inmigrantes y suspender los contingentes anuales poniendo de manifiesto esa concepción utilitarista del trabajador extranjero que ahora, con la crisis económica "estaría de más", por así expresarlo (Izquierdo Escribano, 2010)

En estas circunstancias, muchos ecuatorianos han aprovechado el momento de crecimiento de su país para dejar atrás los miedos e inseguridades de un sistema en dificultad, pudiendo renunciar a pagar la hipoteca a los bancos españoles, recibir dinero para el viaje y ganar seguridad y confianza en el mismo país del que se fueron hace unos años. Esto va a ser una gran oportunidad para transferir el conocimiento y la experiencia adquirida en años vividos como inmigrantes en otro país. Ahora no serán solo las remesas enviadas desde Europa las que generen riqueza, sino también todo lo aprendido en las escuelas y universidades. Las dificultades económicas por las que atraviesa España constituyen el principal motivo de regreso. Desde enero de 2013 hasta enero de 2014, la población ecuatoriana en España ha bajado de 56466 personas. Las provincias más desarrolladas como la de Guayaquil y Quito son las que más han recibido a sus compatriotas retornados. El fuerte desarrollo económico y social que se ha vivido en estas zonas ha permitido la mejora de las condiciones de vida. Como consecuencia de la crisis económica y financiera de los países occidentales, se ha generado un cambio en este tipo de relaciones transnacionales, donde el impactante desarrollo de algunos de los países latinos, como Ecuador, está poniendo en duda la hegemonía del capitalismo, del neoliberalismo y de la privatización como estrategias predominantes de desarrollo.

El trabajo de campo basado en la observación y en la participación activa en proyectos de ayuda social dirigidos a diferentes colectivos de bajos recursos 
y en situación de riesgo de exclusión en la sociedad ecuatoriana, nos permitió conocer el ámbito de la discapacidad, con personas mayores, personas con bajo recursos económicos o en situación de pobreza extrema. Además participamos en proyectos dirigidos a personas que sufren enfermedades catastróficas (afecciones graves, casi siempre incurables, que ponen en peligro constantemente la vida del paciente) y por último en los proyectos de MIDUVI (Ministerio de Desarrollo Urbano y Vivienda) y de la Fundación Manuela Espejo (es un proyecto de la Vicepresidencia que se desarrolla en todo el territorio nacional desde 2009 para la inclusión de personas con discapacidad) en lo relacionado con el derecho a acceder a una vivienda digna.

Estas "inversiones económicas" son inversiones hacia un futuro mejor y justo, forman parte de un plan de desarrollo muy diferente a lo que se promociona en España, donde los recortes y las políticas de austeridad no permiten la inversión en el bienestar humano. Este modelo de desarrollo (o anti-desarro1lo) es contrario a los principios del buen vivir que se promocionan en Ecuador.

\section{Buen vivir, futuro y alternativas}

El poder económico acumulado por los bancos, propietarios de la mayoría de los inmuebles construidos, permite analizar simbólicamente cómo en Europa se está viviendo una vuelta al feudalismo:

Las luchas señoriales no se libran por el dominio de la tierra, sino de la deuda. Y la deuda no es más que tiempo enfeudado. Al endeudarnos, accedemos a nuestro futuro y se lo cedemos al nuevo señor deudal...La hipoteca, el terror securitario, el temor a la epidemia y al extranjero atan a la gente a un territorio y a un amo (Baños Boncompain, 2012, p. 25).

Nos damos cuenta de cómo la necesidad de beneficio de las entidades bancarias, de los constructores, especuladores financieros, empresas de seguros, particulares y en general los modelos de desarrollo neoliberal, superan la lógica de las necesidades humanas, creando una contracción de sentido todavía más confusa por la falta de la posibilidad, para quien lo necesita, de acceder a una vivienda sin hipotecar la vida.

Además es antropológicamente interesante observar cómo, por la falta de recursos económicos y monetarios se está revalorizando la "autonomía alimentaria", tanto para no ser tan dependiente de la "compra al súper-mercado", 
como para comer productos más sanos y ecológicos. Quizás la crisis que se está viviendo desde hace unos años en Occidente, ha activado en las personas la necesidad de no ser tan dependientes de un sistema que empieza a no garantizar el bienestar de sus ciudadanos, sino que dificulta la búsqueda de alternativas para un buen vivir y para cubrir las necesidades básicas. La economía de libre mercado se basa en un sistema con normas que potencian la generación de beneficios basados en la competitividad de los precios, normalmente como resultado de la reducción de los salarios de los trabajadores. Esta es una realidad reconocida por la legislación de numerosos organismos internacionales como la Unión Europea y la Organización Mundial del Comercio, que han contribuido a crear unos comportamientos antisociales de la economía.

Ecuador forma parte del grupo de países latinoamericanos que están transformando sus condiciones económicas, reduciendo la pobreza extrema, aumentando el empleo y practicando políticas del buen vivir. Se están generando movimientos que empujan el desarrollo sostenible con el respeto al medioambiente, al mantenimiento de los recursos del planeta y a las poblaciones indígenas. El presidente del Ecuador, Rafael Correa, participó en la redacción de la Constitución ecuatoriana donde se declara la independencia y el respeto de las culturas de todas las poblaciones indígenas.

Este tipo de modelo de desarrollo tiene poco que ver con los deseos neoliberales de un capitalismo sin fin en un mundo de recursos limitados. El país está implementando políticas económicas y sociales que se acercan más a un modelo de "economía del bien común". Este modelo es una alternativa concreta para reducir las desigualdades evolucionando del concepto de competitividad al de cooperación y ayuda para crear una democracia directa y participativa y eliminar cualquier forma de poder hegemónico que pueda ser perjudicial para el respeto de los derechos fundamentales de la persona y de los pueblos. Para crear los fundamentos de este sistema, primero hay que "cambiar los testimonialmente débiles indicadores monetarios por testimonialmente fuertes indicadores no monetarios" (C. Felber, 2012, p. 33).

Una vez entendido que hay que empezar a valorar y a cambiar las técnicas de evaluación de desarrollo, este cambio tendrá que enfocarse en la dignidad humana, solidaridad, justicia, sostenibilidad medioambiental y democracia. En el nuevo concepto de la "economía del bien común" explicado por Felber, el dinero no es un fin en sí mismo, sino solo un instrumento y esta concepción será útil para eliminar la competitividad del sistema. Además están previstos mecanismos de protección del ser humano, para eliminar la alienación del traba- 
jo gracias a la disminución de horas semanales de trabajo y la toma de un año sabático por cada década de vida laboral. Todo este modelo además de tener en cuenta variables económicas y regenerarlas, toma en consideración la formación psicológica del ser humano a la hora de creer que la lucha y competitividad sean factores naturales; también es un elemento de extrema importancia la "huella ecológica" que hoy en día es demasiado elevada para continuar con un modelo neoliberal en el futuro más próximo.

Un ejemplo piloto viene de otro país Latinoamérica: Bolivia es el primer país del mundo que, en su Constitución de 2009, se ha pronunciado a favor de dar un valor propio a la naturaleza. Algo que tiene "valor propio" no puede ser propiedad de otro (Felber, 2012, p. 83).

Además según este autor hay que modificar también los principios que regulan las políticas monetarias, constituyendo una alternativa democrática directa, fundada en principio en asambleas municipales, que se desarrollan en el territorio de pertenencia, por parte de todos los ciudadanos, para en un segundo momento ampliarse en comités nacionales e internacionales. Las tomas de decisiones se harían según el principio de la total soberanía de los pueblos los cuales elegirán cualquier decisión por votación directa (Felber, 2014).

Analizando estas alternativas si nos centramos en la realidad ecuatoriana, podemos decir que "el Gobierno de la Revolución Ciudadana, recogiendo los planteamientos de los pueblos andino-amazónicos, plantea la noción del Buen Vivir como objetivo central de la política pública" (Domínguez y Caria; 2014, p. 20). Hay unos elementos específicos del modelo del Buen Vivir, muy parecidos a los de la "economía del bien común", aunque el análisis de C. Felber es posterior a la gestación y actuación de las políticas del Buen Vivir, las cuales se pueden resumir según estos principios: armonía con la Naturaleza, reivindicación de los principios y valores de los pueblos ancestrales, satisfacción de las necesidades básicas, justicia social e igualdad como responsabilidades del Estado planificador, y democracia. Estos son elementos que no se limitan a definir las políticas internas de Ecuador, sino también se manifiestan críticos con el modelo occidental a través de la crítica al capitalismo y el anti antropocentrismo.

El Buen Vivir como crítica al paradigma de la modernidad rechaza los fundamentos de la teoría del desarrollo de la corriente principal, que es calificada como occidental, antropocéntrica, capitalista y economicista, en un giro típica- 
mente gramsciano para destruir una hegemonía y crear otra (Domínguez y Caria, 2014, p. 26).

Estos mismos autores critican a las políticas del Buen Vivir, porque corren el riesgo de quedarse en ideología. Según Gramsci la hegemonía se conquista generando el 'consenso activo' de otros grupos a través de un partido político de vanguardia como verdadero intelectual colectivo, el Movimiento País se propone como un bloque intelectual-moral capaz de guiar el país hacía una nueva cultura política. Esta crítica surge de la situación planteada el 4 de octubre de 2013, cuando la Asamblea Nacional del Ecuador aprobó por 108 votos contra 25 la explotación del bloque petrolero en el campo Ishpingo-Tambococha-Tiputini (ITT), ubicado en la reserva de la biosfera de Yasuní, un parque nacional de 982000 hectáreas creado en 1979 y que alberga una de las mayores concentraciones de biodiversidad del planeta.

\section{Conclusión}

A pesar de las críticas y sin renunciar a ellas, Ecuador sigue sirviendo de ejemplo a muchos países occidentales. Cambiar los parámetros de valoración económica en un contexto de economía neoliberal globalizada no es un reto fácil. La voluntad de cambio de los políticos ecuatorianos tiene que sustentarse en una solvencia económica, que paradójicamente, puede llevar a tomar decisiones como la explotación de ITT para implementar los Planes Nacionales para el Buen Vivir (PNBV) 2009-13 y 2013-17 y la creación de la FLOK Society, una nueva herramienta que ayuda al cambio de matriz productiva hacia la sociedad del conocimiento libre, común y abierto, pero que requiere financiación económica en su etapa inicial. Superada esta primera etapa permitirá compartir conocimiento ancestral e indígena a través de software y cultura libre. En concreto es un proceso participativo en red y un proyecto de investigación abierta para crear propuestas de políticas públicas y acciones políticas para la transición de Ecuador hacia la economía social del conocimiento.

FLOK Society presenta una visión alternativa hacia un modelo de sociedad colaborativa y una matriz productiva basada en los bienes comunes, los sistemas peerto-peer, el conocimiento compartido y las prácticas comunitarias tradicionales.

Nos encontramos, en definitiva, con el antagonismo constituyente que ha definido la revolución ciudadana del buen vivir en el ámbito del conocimiento y sus 
soportes cibernéticos: una herencia e imposición colonialista global que imprime un individualismo cognitivo basado en el consumo y transacción del saber en la forma de la propiedad intelectual. A esta herencia se enfrentan, por un lado, las tradiciones indígenas originarias del yachay, de (re)producción de saberes comunitarios y, por otro, las nuevas formas de colaboración del procomún digital de la cultura y la ética hacker. Resuenan los principios de reciprocidad (randi-randi) y organización del trabajo comunitario (maki-maki) en lo que podríamos llamar una Pacha Mama digital del conocimiento ( http://floksociety.org/ ).

Esta podría ser una herramienta para evitar lo que ha pasado en Europa. Solo el conocimiento permitirá la comprensión y la generación de un cambio. "La gestión de la crisis actual por parte de los poderes económicos y políticos están fracturando la sociedad hasta atomizarla, insularizarla e insensibilizarla para anular cualquier posibilidad de reacción empática colectiva" (Antón Hurtado, 2015, p. 89) Apelamos al desarrollo de una conciencia colectiva donde no haya diferencia entre nosotros y los otros. Cuando esta conciencia sale a la luz estamos más predispuestos a prestar atención a los demás, a la sociedad en la cual vivimos y a la naturaleza que nos acoge. Los valores se reorganizan y se ajustan para el bienestar colectivo, el cual permitirá una mayor plenitud y la creación de un sentido comunitario más amplio. A través de la comprensión y la toma de conciencia se podrían restablecer los valores sobre los cuales reconstituir una sociedad más justa, equilibrada y sostenible, basada en la relación entre la comunidad, que sustenta el sentimiento identitario y el territorio, entendido éste como "paisaje cultural", sobre el que se fundamenta el sentimiento de arraigo. Una relación construida con una perspectiva que no sea la de la competitividad sino colaborativa y empática. 


\section{Anexos}

Tablas

Tabla 1

Entradas y salidas en Ecuador de ecuatorianos hacia y desde España (2008-2013)

\begin{tabular}{|l|l|l|}
\hline & \multicolumn{1}{|c|}{ Entradas } & \multicolumn{1}{c|}{ Salidas } \\
\hline 2008 & 110062 & 132868 \\
\hline 2009 & 134967 & 110446 \\
\hline 2010 & 113709 & 99466 \\
\hline 2011 & 130803 & 112575 \\
\hline 2012 & 122013 & 101557 \\
\hline
\end{tabular}

Elaboración propia a partir de datos INEC, Anuario de estadísticas de entradas y salidas internacionales 2013

Tabla 2

Flujo de inmigración procedente del Ecuador (2008-2014)

\begin{tabular}{|l|l|}
\hline & \multicolumn{1}{c|}{ Ecuatorianos emigrados a España } \\
\hline 2008 & 32464 \\
\hline 2009 & 13512 \\
\hline 2010 & 6939 \\
\hline 2011 & 6523 \\
\hline 2012 & 5581 \\
\hline 2013 & 5262 \\
\hline 2014 & 2445 \\
\hline
\end{tabular}

Elaboración propia a partir de datos INE, Migraciones exteriores desde 2008 hasta 2014

Tabla 3

Hipotecas concedidas en España (2007-2014)

\begin{tabular}{|l|l|}
\hline & \multicolumn{1}{|c|}{ Número de hipotecas concedidas } \\
\hline 2007 & 431043 \\
\hline 2008 & 350898 \\
\hline 2009 & 319766 \\
\hline 2010 & 272083 \\
\hline 2011 & 186147 \\
\hline 2012 & 137379 \\
\hline 2013 & 97903 \\
\hline 2014 & 73044 \\
\hline
\end{tabular}

Elaboración propia a partir de datos INE España 2015, Hipotecas constituidas sobre el total de fincas por naturaleza de la finca 2015 
Tabla 4

Entradas de ecuatorianos (Periodo 2008 - 2013)

\begin{tabular}{|l|l|}
\hline & \multicolumn{1}{|c|}{ Retornados } \\
\hline 2008 & 767469 \\
\hline 2009 & 820292 \\
\hline 2010 & 893408 \\
\hline 2011 & 1027543 \\
\hline 2013 & 1025310 \\
\hline
\end{tabular}

Elaboración propia a partir de datos INEC, Anuario de estadísticas de entradas y salidas internacionales 2013

\section{Gráficos}

\section{Gráfico 1}

Entradas y salidas en Ecuador de ecuatorianos hacia y desde España (2008-2013)

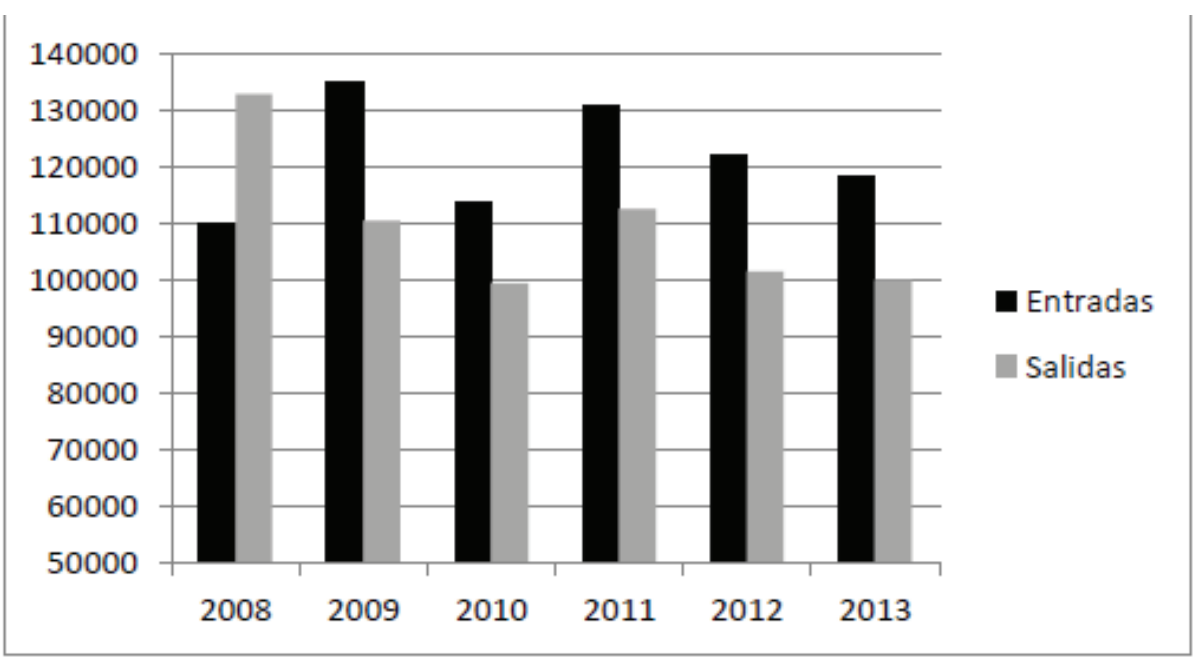

Elaboración propia a partir de datos INEC, Anuario de estadísticas de entradas y salidas internacionales 2013 
Gráfico 2

Flujo de inmigración procedente del Ecuador (2008-2014)

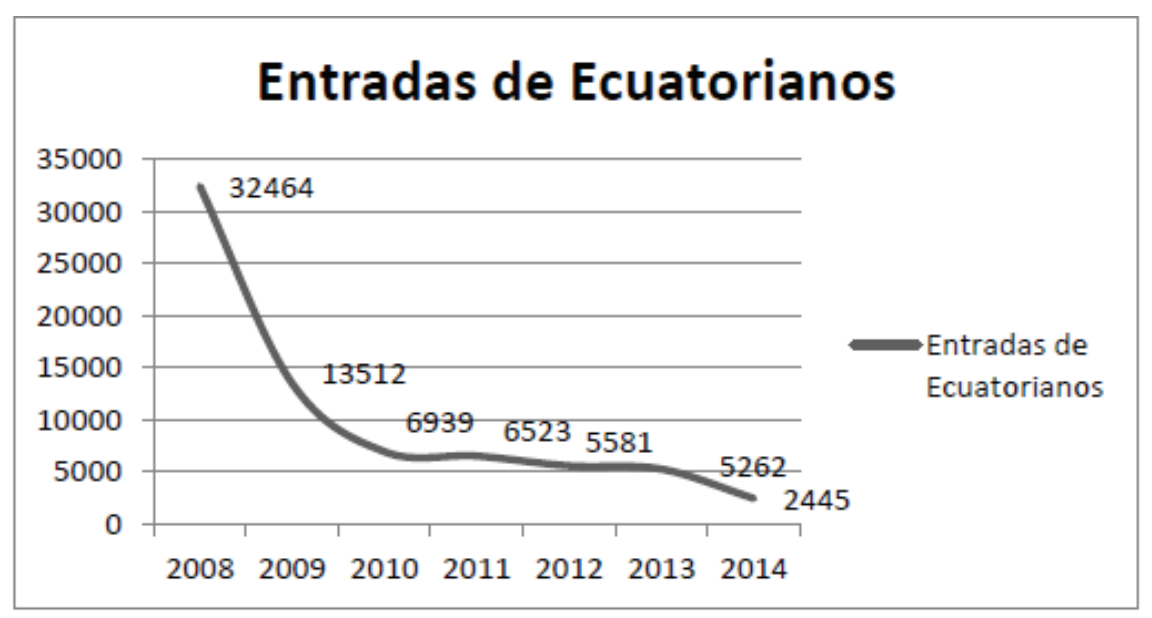

Elaboración propia a partir de INE España, Migraciones exteriores desde 2008 hasta 2014

\section{Gráfico 3}

Hipotecas concedidas España (2007-2014)

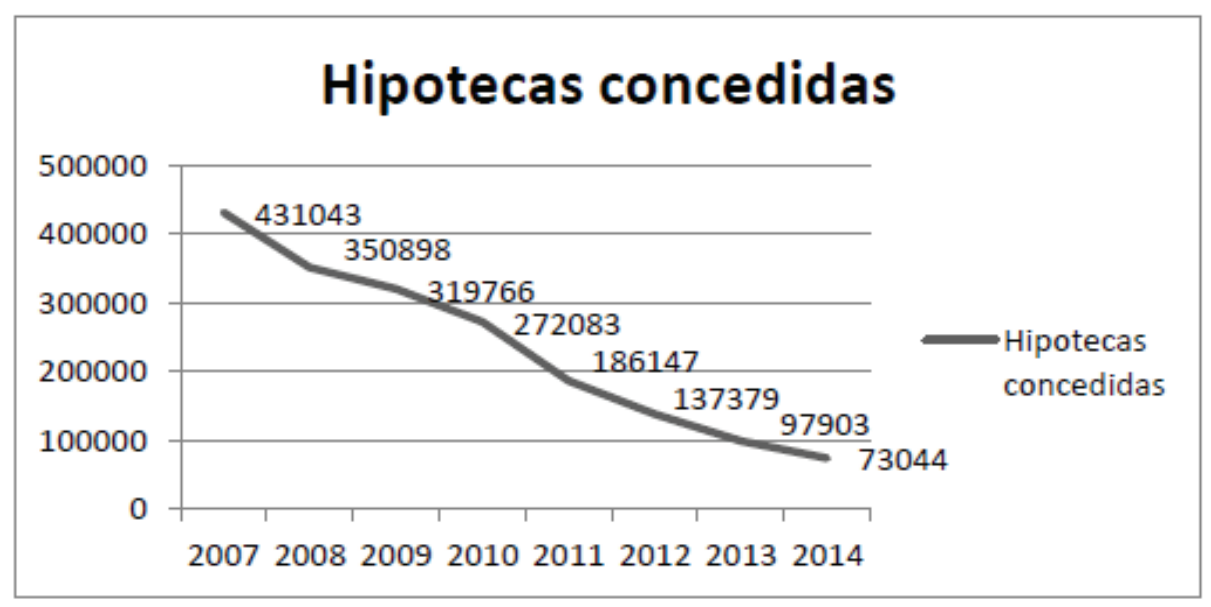

Elaboración propia a partir de datos INE 2015, Hipotecas constituidas sobre el total de fincas por naturaleza de la finca 2015 


\section{Bibliografía}

Álvarez Munárriz, Luis (2011). La categoría de paisaje cultural. AIBR Revista de Antropología Iberoamericana, 6(1).

Antón Hurtado, Fina (2012). Antropología del sinsentido. Revista de Antropología Experimental, 12, Texto 27, 349-371, España.

(2013). Aproximación antropológica a la seguridad. Universitas, XI(19), juliodiciembre, 73-100. Quito: Editorial Abya Yala/Universidad Politécnica Salesiana.

(2015). Antropología del miedo. Methaodos. Revista de Ciencias Sociales, 3(2), 262-275, España.

Baños Boncompain, Antonio (2012). Posteconomia. Barcelona: Los libros del lince.

Beck, Ulrich (1998) Políticas ecológicas en la edad del riesgo. Barcelona: El Roure Editorial.

(2000). Un nuevo mundo feliz. Madrid: Paidos.

(2002). La sociedad del riesgo global. Madrid: Paidos.

Bourdieu, Pierre (2003). Las estructuras sociales de la economía. Buenos Aires: El Manantial.

Castells, Manuel (2005). La era de la información V1 La sociedad red. Barcelona: Alianza Editorial.

Constitución del Ecuador 2008.

Constitución Española 1978.

Domínguez, Rafael y Caria, Sara (2014). La ideología del Buen Vivir: la metamorfosis de una 'alternativa al desarrollo' en desarrollo de toda la vida. Pre-textos para el Debate, 2. Universidad Andina Simón Bolívar.

Economistas Frente la Crisis (2012). No es economía, es ideología. Madrid: Deusto.

Felber, Christian (2012). La Economía del Bien Común. Madrid: Epublibre. (2014). Dinero. De fin a medio. Madrid: Duesto.

Herrera, Gioconda (2004). Elementos para una comprensión de las familias transnacionales. En: Francisco Hidalgo (Ed.), Migraciones. Un juego con cartas marcadas, pp. 215- 232. Quito: Abya-Yala.

INE (2014). "Migraciones exteriores desde 2008 hasta 2014".

(2015). "Hipotecas constituidas sobre el total de fincas por naturaleza de la finca 2015 ".

INEC (2013). “Anuario de estadísticas de entradas y salidas internacionales 2013”.

Izquierdo Escribano, Antonio (2010). El modelo de inmigración y los riesgos de exclusión. En: Informe Foessa, Cap. 7. 
Ministerio del Interior de España (2002).

Montero, Gabriela (2006). Las representaciones sociales de los emigrantes ecuatorianos en España sobre el proceso migratorio. Revistas alternativas, Cuadernos de Trabajo Social, 14.

Pedone, Claudia (2002). Las representaciones sociales en torno a la emigración ecuatoriana a España. Iconos, 14. Quito: FLACSO.

Programa de las Naciones Unidas para el Desarrollo [PNUD] (2009). Informe sobre Desarrollo Humano. Superando barreras: movilidad y desarrollo humanos. Madrid: Mundi-Prensa Libros.

Sutcliffe, B. (1998). Nacido en otra parte. Un ensayo sobre la migración internacional, el desarrollo y la equidad. Bilbao: Hegoa.

\section{Páginas Web}

Agencia EL PAIS (2014). “La salida de inmigrantes reduce la población en España por segundo año".

http://sociedad.elpais.com/sociedad/2014/06/30/actualidad/1404121049_262083.html, [15 agosto 2014].

Benito, R. (2012). “Correa impide por ley que bancos españoles embarguen a sus ciudadanos"

http://www.elconfidencial.com/sociedad/2012/11/17/correa-impide-por-ley- que-bancos-espanoles-embarguen-a-sus-ciudadanos-en-ecuador-109327, [17 noviembre 2012].

Consulado General del Ecuador en Madrid,

http://madrid.consulado.gob.ec/apoyo-en-casos-de-vulnerabilidad/, [25 junio 2014].

http://floksociety.org/

Betim, F. (2014). "Mamá quiero quedarme en España".

http://politica.elpais.com/politica/2014/12/27/actualidad/1419711832_735107.html, [27 diciembre 2014].

Carbajosa, A. (2014). “Una sangría demográfica sin precedentes”. http://politica.elpais. com/politica/2014/06/30/actualidad/1404150606_298845.html, [30 junio 2015]. 